\section{(6) OPEN ACCESS}

\title{
Ten days of simulated live high:train low altitude training increases Hbmass in elite water polo players
}

\author{
Laura A Garvican-Lewis, ${ }^{1,2}$ Sally A Clark, ${ }^{2}$ Ted Polglaze, ${ }^{2}$ Greg McFadden, ${ }^{2}$ \\ Christopher J Gore ${ }^{1,2,3}$
}

${ }^{1}$ National Institute of Sports

Studies, University of Canberra, Canberra, Australia

${ }^{2}$ Department of Physiology, Australian Institute of Sport, Canberra, Australia

${ }^{3}$ Exercise Physiology Laboratory, Flinders University of South Australia, Adelaide, Australia

\section{Correspondence to} Dr Laura A Garvican-Lewis, National Institute of Sports Studies, University of Canberra, Bruce, ACT 2601, Australia; laura.garvican@ausport.gov.au

Accepted 10 September 2013

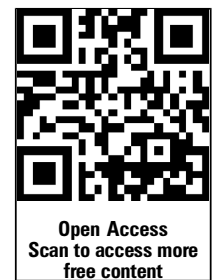

To cite: Garvican-Lewis LA, Clark SA, Polglaze T, et al. Br J Sports Med 2013;47: i70-i73.

\section{ABSTRACT}

Objectives Water polo requires high aerobic power to meet the demands of match play. Live high:train low (LHTL) may enhance aerobic capacity at sea level. Before the Olympics, the Australian women's water polo team utilised LHTL in an attempt to enhance aerobic fitness. Methods Over 6 months, 11 players completed three normobaric LHTL exposures (block 1:11 days at $3000 \mathrm{~m}$; block $2+3: 9$ days at $2500 \mathrm{~m}, 11$ days normoxia, 10 days at $2800 \mathrm{~m}$ ). Haemoglobin mass (Hbmass) was measured through carbon monoxide-rebreathing. Before each block, the relationship between Hbmass and water polospecific aerobic fitness was investigated using the Multistage Shuttle Swim Test (MSST). Effect size statistics were adopted with likely, highly likely and almost certainly results being $>75 \%,>95 \%$, $>99 \%$, respectively. A Pearson product moment correlation was used to characterise the association between pooled data of Hbmass and MSST.

Results Hbmass (mean \pm SD, pre $721 \pm 66 \mathrm{~g}$ ) likely increased after block 1 and almost certainly after block $2+3$ (\% change; $90 \%$ confidence limits: block 1: $3.7 \%$; 1.3-6.2\%, block 2+3: $4.5 \%$; 3.8-5.1\%) and the net effect was almost certainly higher after block $2+3$ than before block 1 (pre) by $8.5 \% ; 7.3-9.7 \%$. There was a very large correlation between $\mathrm{Hbmass}(\mathrm{g} / \mathrm{kg})$ and MSST score $(r=0.73)$.

Conclusions LHTL exposures of $<2$ weeks induced approximately $4 \%$ increase in Hbmass of water polo players. Extra Hbmass may increase aerobic power, but since match performance is nuanced by many factors it is impossible to ascertain whether the increased Hbmass contributed to Australia's Bronze medal.

\section{INTRODUCTION}

Water polo is a dynamic intermittent team sport, requiring a high aerobic power to meet the highintensity demands of the game. ${ }^{12}$ When in the pool, field players are continuously involved in match play; requiring them to swim repeatedly from end to end, interspersed with high-intensity actions, including jumping, wrestling and sprinting. ${ }^{2}$ Indeed, the frequent occurrence of high-intensity activity bouts highlights the ability to perform such actions as an important facet of the game. ${ }^{2}$ Recovery from highintensity actions requires the repletion of phosphocreatine which in turn, is reliant on aerobic metabolism. Therefore, a high aerobic power may also benefit repeat-sprint ability ${ }^{3}$ as well as improving overall match fitness.

Continuous swimming and small-sided games are routine training methods of elite water polo players; however, repetitive load on the shoulder carries increased injury risk. ${ }^{5} 6$ Therefore, novel interventions or activities which have potential to enhance aerobic capacity without increasing musculoskeletal load are attractive to team sports such as water polo, particularly in an Olympic year when player retention is critical.

Live high:train low (LHTL) altitude training is a popular training modality among endurance athletes and may enhance aerobic capacity at sea level ${ }^{7}$ through increase in haemoglobin mass (Hbmass). ${ }^{8}$ Although high-altitude training is not widely used by team sports as a means of enhancing intermittent high-intensity activity, ${ }^{9}$ a traditional live high: train High (LHTH) approach has been successfully utilised by some Australian rules football clubs in the preseason, ${ }^{10}$ showing promise as an effective intervention for enhancing aerobic fitness at sea level.

Before the 2012 Olympics, the Australian women's water polo team utilised simulated LHTL in an attempt to enhance aerobic fitness. Here, we document the changes in Hbmass during three LHTL exposures.

\section{METHODS \\ Subjects}

The 2012 Olympic women's water polo training squad consisted of 20 players (4 goal keepers and 16 field players). Of these, altitude training was deemed as 'high risk' for five field players due to training age (junior athletes), illness or injury. The physical characteristics of the remaining 11 field players who engaged in altitude training were; age: $25.4 \pm 2.9$ year, height: $178.0 \pm 6.6 \mathrm{~cm}$ and body mass: $77.8 \pm 10.8 \mathrm{~kg}$. Athletes gave written informed consent before participating.

\section{Altitude exposure}

Over 6 months (October-March), a total of three simulated LHTL exposures were planned, comprising of $14 \mathrm{~h} /$ day at $2500-3000 \mathrm{~m}$, in a five-bedroom normobaric hypoxic facility at the Australian Institute of Sport (AIS, Canberra, Australia) as follows: block 1 ( $n=9$, October) comprised 11 days at $3000 \mathrm{~m}$, (preseason); block $2+3 \quad(\mathrm{n}=11$, February-March) comprised 9 days at $2500 \mathrm{~m}$ followed by 11 days normoxia (at home) and then 10 days at $2800 \mathrm{~m}$, (6 weeks preinternational competition). During each altitude block, all training sessions, including water polo, swimming and weight training, were conducted in mild hypoxia (Canberra, $580 \mathrm{~m}$ ). Venous blood was obtained at rest from an antecubital forearm vein prior to each altitude exposure to ascertain serum ferritin, with analysis performed on an Integra 400 (Roche Diagnostics, Switzerland) automated biochemistry analyser. All athletes were supplemented with oral 
iron daily throughout each camp (ferrous sulphate $305 \mathrm{mg}$ ). Athletes identified as iron deficient (serum ferritin $<35 \mu \mathrm{g} / \mathrm{L}$ ) prior to block 1 were instructed to continue supplementation between blocks 1 and 2, with serum ferritin levels assessed again prior to block $2+3$.

\section{Haemoglobin mass}

Hbmass was measured using the optimised 2 min CO-rebreathing technique $^{11}$ on five occasions: pre (before block 1), postblock 1, 2 weeks postblock 1 , before block 2 and after block 3 .

A CO bolus of $1.2 \mathrm{~mL} / \mathrm{kg}$ body mass was rebreathed with $3 \mathrm{~L}$ of $100 \%$ oxygen for $2 \mathrm{~min}$ using a glass spirometer. Carboxyhaemoglobin (HbCO) concentration of capillary blood (finger-tip) was analysed using an OSM 3 hemoximeter (Radiometer, Copenhagen, Denmark) before and $7 \mathrm{~min}$ after inhalation of the bolus with the change in $\mathrm{HbCO}$ used to calculate Hbmass as described previously. ${ }^{12} 13$ The typical error for this test in our hands is $1.8 \% .^{14}$

\section{Multistage shuttle swim test}

At the start of blocks 1 and 2, aerobic fitness of all field players was assessed using the Multistage Shuttle Swim test (MSST). ${ }^{15}$ Players were required to continuously swim a series of $10 \mathrm{~m}$ shuttles between two lane ropes within a progressively decreasing cued time frame. The time allowed for each shuttle was reduced approximately every minute, with the swimming velocity required to meet each cue increased by $0.05 \mathrm{~m} / \mathrm{s}$. Players were removed from the test when they failed to be within one stroke of the lane rope on two consecutive occasions. The test has previously been validated with elite water polo players, with aerobic power shown to account for $78 \%$ of variance for MSST score. ${ }^{15}$ Further, the MSST is a suitable tool for discriminating players of different positions and playing standards ${ }^{16}$ as well as a valid method for obtaining maximum heart rate. ${ }^{17}$ Unfortunately, due to time and training constraints it was not possible to assess MSST following each hypoxic block. Therefore the effect of LHTL on aerobic fitness could not be determined.

\section{Statistics}

A contemporary approach to statistics was adopted since small changes in performance can be meaningful in athletes. ${ }^{18}$ Differences and associated $90 \%$ confidence limits (CL), in Hbmass changes after each altitude exposure were estimated to define the practical significance of the results, as opposed to a traditional significance and hypothesis testing. The magnitude of change within each block, as well as compared with premeasures was expressed as a standardised mean difference (Cohen effect sizes) computed as the difference in the mean divided by the between-subject SE, where a small effect is $>0.2$, moderate $>0.6$ and a large effect $>1.2$. The smallest worthwhile change was derived from Cohen's Scale for effect sizes in which a small effect is $\geq 0.2$. Clear effects $>75 \%$ likely positive were considered substantial, with the following descriptors attributed accordingly: 75-95\%, likely; 95-99\%, very likely; >99\%, almost certainly. ${ }^{18}$

A Pearson product moment correlation was used to characterise the association between Hbmass and MSST. Data for every field player who conducted both the MSST and an Hbmass test at the same time point were pooled, regardless of whether the player subsequently engaged in the LHTL block. Pooled data comprised of 9 players prior to block 1 and 14 players prior to block 2. Effect sizes of correlation coefficients were defined as follows: trivial 0.0 ; small $0.1-0.3$; moderate $0.3-0.5$; large $0.5-$ 0.7 ; very large $0.7-0.9$; nearly perfect 0.9 and perfect $1.0 .^{18}$

Data are expressed as the mean and SD unless otherwise stated. Data in graphs are presented as per cent changes from baseline measures.

\section{RESULTS}

Prior to the first exposure mean (pre; mean \pm SD) Hbmass and ferritin were $721 \pm 66 \mathrm{~g}(9.4 \pm 0.7 \mathrm{~g} / \mathrm{kg})$ and $50.6 \pm 28.8 \mu \mathrm{g} / \mathrm{L}$, respectively. A likely small increase in Hbmass (figure 1) was observed after block 1 (\% change; 90\% CL, effect size: block 1: $3.7 \% ; 1.3-6.2 \%, 0.37)$ and remained 2 weeks later $(4.0 \% ; 1.9$ $6.1 \%, 0.40)$. Similarly, following block $2+3$, an almost certainly small increase in Hbmass was observed $(4.5 \%$; 3.8-5.1\%, 0.41) and was almost certainly moderately higher compared to prevalues $(8.5 \% ; 7.3-9.7 \%, 0.87$; figure 2$)$.

Five players were identified at the start of block 1 as being iron deficient (ferritin $<35 \mu \mathrm{g} / \mathrm{L}$ ). At the start of block 2, mean ferritin had increased to $70.2 \pm 37.2 \mu \mathrm{g} / \mathrm{L}$ with only two players $<35 \mu \mathrm{g} / \mathrm{L}$.

A very large correlation was observed between Hbmass $(\mathrm{g} / \mathrm{kg})$ and MSST score $(r=0.73$; figure 3$)$.

\section{DISCUSSION}

The main finding of the present study was small but worthwhile changes in Hbmass of elite female water polo players were observed following simulated LHTL altitude exposures of 10-11 days.

\section{Hbmass response}

Previously, an increase in Hbmass of $1 \%$ per $100 \mathrm{~h}$ of exposure to either natural or simulated altitude has been documented ${ }^{19}{ }^{20}$; leading to current recommendations for endurance athletes engaging in altitude training to aim for exposures of at least 2-3 weeks at greater than $2500 \mathrm{~m} .{ }^{21}$ To our knowledge, the only other published data available showing Hbmass changes in team sport athletes after altitude training documents approximately 3\% increase in Australian Rules football players after a 19-day training camp at $2130 \mathrm{~m} .{ }^{10}$ The substantial erythropoietic response observed in these water polo players after a hypoxic

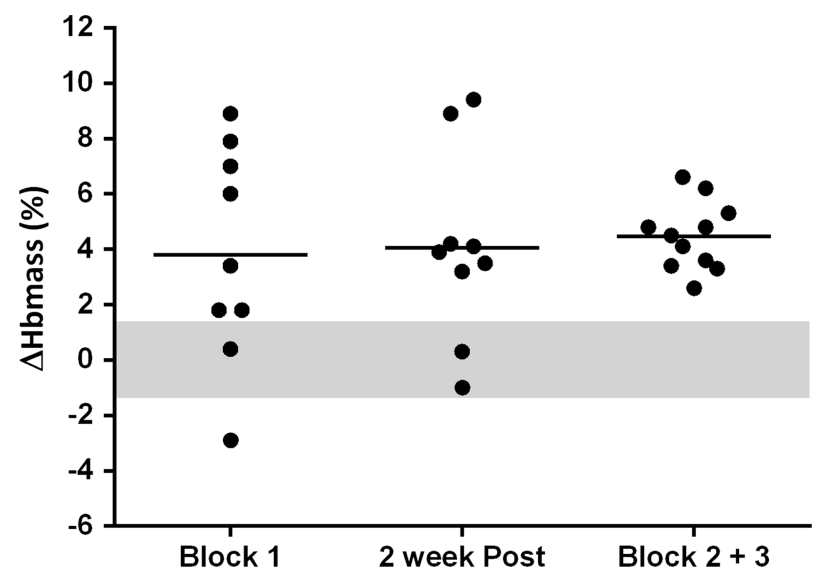

Figure 1 Individual (black circles) and mean changes (solid line) in haemoglobin mass (Hbmass) following each simulated live high: train low altitude exposure. Block 1: change in Hbmass following 11 days at 3000 m; 2 week post: changes in Hbmass versus premeasured 2 weeks post block 1; block 2+3: change in Hbmass following 9 days at $2500 \mathrm{~m}$, followed by 11 days in normoxia then 10 days at $2800 \mathrm{~m}$. Shaded area indicates typical error of Hbmass measurement. 


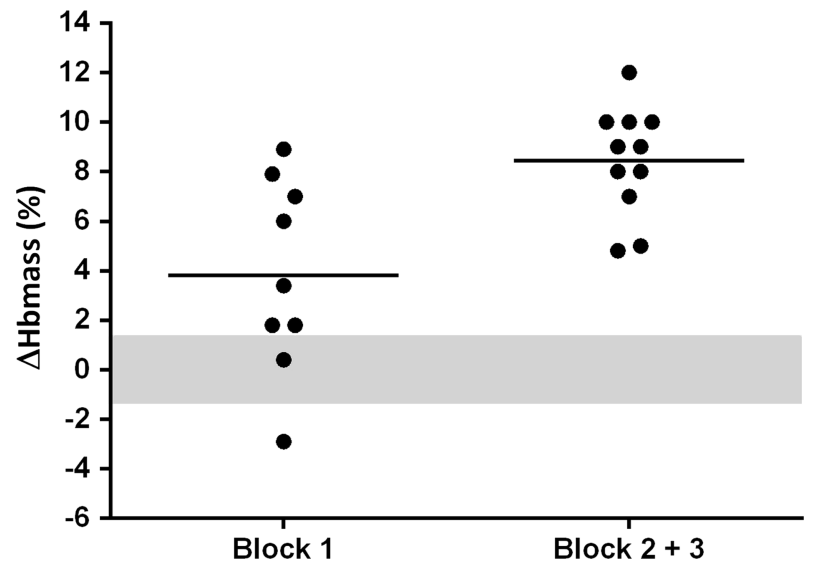

Figure 2 Individual (black circles) and mean changes (solid line) in haemoglobin mass (Hbmass) following each simulated live high: train low altitude exposure compared to preseason values. Block 1:11 days at $3000 \mathrm{~m}$; block 2+3: change in Hbmass following 9 days at $2500 \mathrm{~m}$, followed by 11 days in normoxia then 10 days at $2800 \mathrm{~m}$. Shaded area indicates typical error of Hbmass measurement.

dose of only $150-160 \mathrm{~h}$ is therefore surprising, but may be explained by the lower relative Hbmass of the players compared with elite endurance athletes. ${ }^{22} 23$ It should also be noted that the Hbmass time course and dose-response data available largely refers to endurance athletes and may not directly translate to athletes required to perform intermittent activity (eg, team sport). However, if the aerobic system of these 'intermittent' athletes is not maximally adapted through training, ${ }^{24}$ such athletes may present with a greater capacity for adaptation than previously expected. Further, the daily energy availability of team sport athletes may assist to create an optimal state of erythropoiesis ${ }^{25}$ compared with endurance athletes who may restrict energy intake.

The substantial and somewhat rapid Hbmass response observed may also be related to the timing of each block during the season. The players started block 1 in the base phase of training, 1 month after the annual training break or 'off-season'. The exposure may have accelerated base phase training adaptations that usually occur over several weeks to months. ${ }^{26} 27$ Interestingly, large changes were observed after block $2+3$, which was positioned in the precompetition phase. In the absence of altitude training, such changes mid-season would

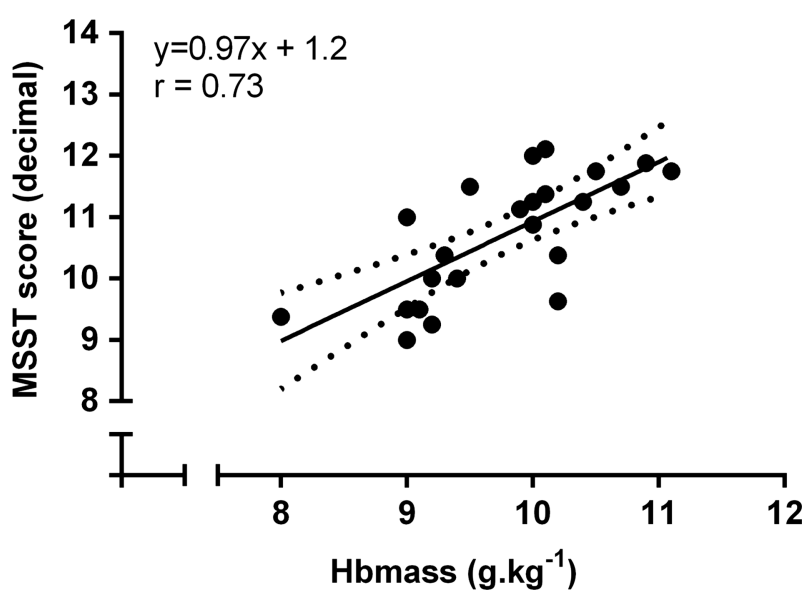

Figure 3 Relationship between haemoglobin mass (Hbmass) and the Multistage Shuttle Swim Test (MSST). Dotted lines indicate the 95\% confidence band of regression line. have required a substantial increase in training load-a $10 \%$ change in training load of elite cyclists has previously been related to only a $1 \%$ increase in Hbmass. ${ }^{14}$ Thus, in blocks 1 and $2+3$, the use of simulated altitude training served to induce haematological adaptations that could potentially enhance oxygen transport capacity without requiring an increase in musculoskeletal load, and potentially decreasing injury risk. ${ }^{5}$ In a practical setting, the use of simulated LHTL may reduce the need for extensive swimming (or running for land-based sports), assisting in reducing the incidence of injury and induced fatigue, providing more time for skill-based and decision making drills.

A number of confounding situations have been identified which may blunt an erythropoietic response to altitude exposure-namely iron deficiency, illness, inflammation or insufficient energy availability. ${ }^{28}$ Five athletes were identified with serum ferritin $<35 \mu \mathrm{g} / \mathrm{L}$ prior to the first exposure, and it is possible that their Hbmass response was blunted, despite the players being supplemented with oral iron. Indeed, the mean increase in Hbmass following block $2+3$ was greater and coincided with a higher mean ferritin of the players at the start of the exposure, with only two players $<35 \mu \mathrm{g} / \mathrm{L}$.

\section{Hbmass and MSST score}

The relationship between Hbmass and $\mathrm{VO}_{2 \max }$ has been described previously. ${ }^{29}$ The slope of the regression line suggests that at maximal performance, a $1 \mathrm{~g}$ increase in Hbmass is associated with an increase in $\mathrm{VO}_{2 \max }$ of $4 \mathrm{~mL} / \mathrm{min}$. In the present study, MSST score was used as a surrogate for $\mathrm{VO}_{2 \max }$, displaying a strong correlation, and suggesting that increase in Hbmass may enhance aerobic power in these players. Unfortunately, since the MSST was not performed following each exposure we are unable to determine whether the observed changes in Hbmass did indeed result in improved water polo-specific fitness. What's more, whether altitude training induced adaptations, or indeed changes in fitness per se, translate to an improvement in team sport performance is near impossible to determine, due to the complexity of team sport play. ${ }^{30}$

At the 2012 Olympic games, the Australian team were required to play three games in succession which were extended into 'extra-time,' and ultimately won the bronze medal. Aerobic fitness was thus one of many important components in their preparation and performance.

\section{Limitations}

The present study documents a real world example of LHTL use by elite team sport athletes. However, the lack of a control group presents a limitation which must be acknowledged when interpreting our findings; since it is not known how much of the observed increase in Hbmass could have been achieved through training alone. The lack of a post-LHTL assessment of aerobic fitness is also a limitation of the study. Without such data we are unable to determine whether the LHTL exposures resulted in improved aerobic fitness in addition to the enhanced Hbmass observed, and thus scientific conclusions on the effectiveness of LHTL in this instance are difficult.

\section{CONCLUSION}

Relatively short duration exposures of simulated LHTL altitude training induced small increases in the Hbmass of elite women water polo players before the 2012 Olympics, which are likely to be beneficial to aerobic power and repeat sprint ability. However, since match performance is nuanced by many factors, including skill, tactics and refereeing decisions, it is impossible to ascertain whether the increased Hbmass contributed to 
Australia's bronze medal performance in London. Future research should investigate the relationship between altitude-induced changes in Hbmass and match fitness of team sport athletes.

\section{What are the new findings?}

- Ten days of simulated live high:train low altitude training increased haemoglobin mass (Hbmass) of iron supplemented elite women water polo players by $3-4 \%$.

- The time course of the erythropoietic response to simulated altitude may be different for athletes engaged in high-intensity intermittent activity (such as team sport) as opposed to endurance athletes and may have implications for the optimal timing and hypoxic dose for team sports.

- Hbmass of water polo players is strongly related to water polo-specific aerobic fitness.

\section{How might the findings impact on clinical practice in the} near future?

- Simulated live high:train low may provide an alternative means of increasing oxygen transport capacity (through haemoglobin mass) in water polo players without inducing musculoskeletal load; however, whether these adaptations translate to improved match fitness or performance remains to be elucidated.

- Iron status should be assessed in all athletes prior to engaging in altitude training.

- Team sport athletes may not require the same hypoxic dose as endurance athletes.

Contributors LG, GM and TP were responsible for conception and design. $L G$ and GM were involved in the acquisition of the data or analysis. LG, GM, SC, TP and CG were responsible for the interpretation of the data. LG, GM, SC, TP and CG were involved in drafting the article or revising it critically for important intellectual content. LG, GM, SC, TP and CG were responsible for the final approval of the version to be published.

\section{Competing interests None.}

Ethics approval Australian Institute of Sport Human Ethics Committee.

Provenance and peer review Not commissioned; externally peer reviewed.

Open Access This is an Open Access article distributed in accordance with the Creative Commons Attribution Non Commercial (CC BY-NC 3.0) license, which permits others to distribute, remix, adapt, build upon this work non-commercially, and license their derivative works on different terms, provided the original work is properly cited and the use is non-commercial. See: http://creativecommons.org/ licenses/by-nc/3.0/

\section{REFERENCES}

1 Bangsbo J, Mohr M, Krustrup P. Physical and metabolic demands of training and match-play in the elite football player. J Sports Sci 2006;24:665-74.
2 Tan F, Polglaze T, Dawson B. Activity profiles and physical demands of elite women's water polo match play. J Sports Sci 2009;27:1095-104.

3 Sahlin K, Harris RC, Hultman E. Resynthesis of creatine phosphate in human muscle after exercise in relation to intramuscular $\mathrm{pH}$ and availability of oxygen. Scand J Clin Lab Invest 1979:39:551-8.

4 Spencer M, Bishop D, Dawson B, et al. Physiological and metabolic responses of repeated-sprint activities:specific to field-based team sports. Sports Med 2005;35:1025-44.

5 Mountjoy M, Junge A, Alonso JM, et al. Sports injuries and illnesses in the 2009 FINA World Championships (Aquatics). Br J Sports Med 2010;44:522-7.

6 Webster MJ, Morris ME, Galna B. Shoulder pain in water polo: a systematic review of the literature. J Sci Med Sport 2009;12:3-11.

7 Bonetti DL, Hopkins WG. Sea-level exercise performance following adaptation to hypoxia: a meta-analysis. Sports Medicine 2009:39:107-27.

8 Levine BD, Stray-Gundersen J. Point: positive effects of intermittent hypoxia (live high:train low) on exercise performance are mediated primarily by augmented red cell volume. J Appl Physiol 2005;99:2053-5.

9 Billaut F, Gore CJ, Aughey RJ. Enhancing team-sport athlete performance: is altitude training relevant? Sports Med 2012;42:751-67.

10 McLean BD, Buttifant D, Gore CJ, et al. Physiological and performance responses to a pre-season altitude training camp in elite team sport athletes. Int I Sports Physiol Perform 2013;8:391-9.

11 Schmidt W, Prommer N. The optimised CO-rebreathing method: a new tool to determine total haemoglobin mass routinely. Eur J Appl Physiol 2005;95:486-95.

12 Burge CM, Skinner SL. Determination of hemoglobin mass and blood volume with CO: evaluation and application of a method. J Appl Physiol 1995;79:623-31.

13 Gore CJ, Hopkins WG, Burge CM. Errors of measurement for blood volume parameters: a meta-analysis. J App/ Physiol 2005;99:1745-58.

14 Garvican LA, Martin DT, McDonald W, et al. Seasonal variation of haemoglobin mass in internationally competitive female road cyclists. Eur J Appl Physiol 2010;109:221-31.

15 Rechichi C, Dawson B, Lawrence SR. A multistage shuttle swim test to assess aerobic fitness in competitive water polo players. J Sci Med Sport 2000;3:55-64.

16 Tan FH, Polglaze T, Dawson B, et al. Anthropometric and fitness characteristics of elite Australian female water polo players. J Strength Cond Res 2009;23:1530-6.

17 Tan FH, Polglaze T, Dawson B. Comparison of progressive maximal swimming tests in elite female water polo players. Int J Sports Physiol Perform 2009;4:206-17.

18 Hopkins WG, Marshall SW, Batterham AM, et al. Progressive statistics for studies in sports medicine and exercise science. Med Sci Sports Exerc 2009:41:3-13.

19 Clark SA, Quod MJ, Clark MA, et al. Time course of haemoglobin mass during 21 days live high: train low simulated altitude. Eur J Appl Physiol 2009;106:399-406.

20 Garvican L, Martin D, Quod M, et al. Time course of the hemoglobin mass response to natural altitude training in elite endurance cyclists. Scand J Med Sci Sports 2012;22:95-103

21 Wilber RL. Application of altitude/hypoxic training by elite athletes. Med Sci Sports Exerc 2007;39:1610-24.

22 Rasmussen $\mathrm{P}$, Siebenmann C, Diaz V, et al. Red cell volume expansion at altitude: a meta-analysis and Monte Carlo simulation. Med Sci Sports Exerc 2013:45:1767-72.

23 Robach $\mathrm{P}$, Lundby $\mathrm{C}$. Is live high-train low altitude training relevant for elite athletes with already high total hemoglobin mass? Scand J Med Sci Sports 2012;22:303-5.

24 Brotherhood J, Brozovic B, Pugh LG. Haematological status of middle- and long-distance runners. Clin Sci Mol Med 1975;48:139-45.

25 Hung SC, Tung TY, Yang CS, et al. High-calorie supplementation increases serum leptin levels and improves response to rHuEPO in long-term hemodialysis patients. Am J Kidney Dis 2005:45:1073-83.

26 Sawka MN, Muza SR, Young AR. Erythrocyte volume expansion and human performance. In: Fourcroy JL. ed. Pharmacology, doping and sports: a scientific guide for athletes, coaches, physicians, scientists and administrators. New York, NY: Routledge, 2009:125-34.

27 Schmidt W, Prommer N. Effects of various training modalities on blood volume. Scand J Med Sci Sports 2008;18(Suppl 1):57-69.

28 Stray-Gundersen J, Levine BD. 'Living high and training low' can improve sea level performance in endurance athletes. Br J Sports Med 1999;33:150-1.

29 Schmidt W, Prommer N. Impact of alterations in total hemoglobin mass on $\mathrm{VO}_{2 \max }$. Exerc Sport Sci Rev 2010;38:68-75.

30 Buchheit M, Simpson BM, Mendez-Villanueva A. Repeated high-speed activities during youth soccer games in relation to changes in maximal sprinting and aerobic speeds. Int J Sports Med 2013:34:40-8. 